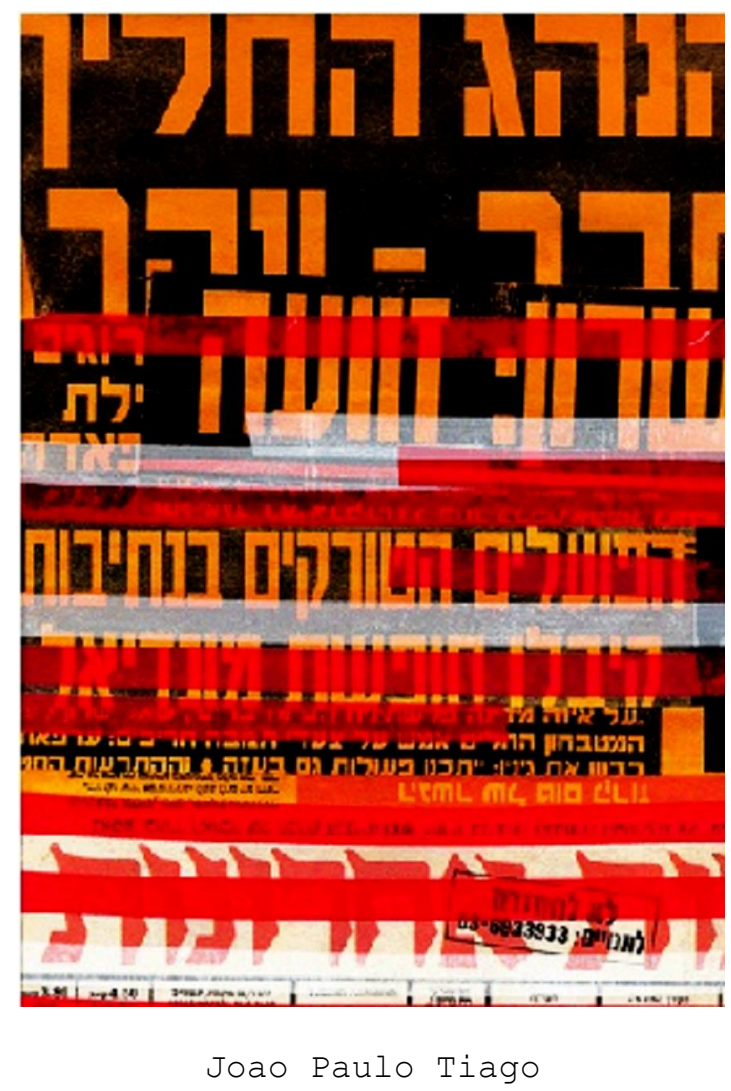

\title{
Literatura e cinema: \\ visualidade e montagem nas escrituras de Sérgio Sant'Anna e João Gilberto Noll
}

\section{Maria Isaura Rodrigues Pinto}

Doutora em Literatura Comparada pela Universidade Federal Fluminense. Professora do Departamento de Letras da Faculdade de Formação de Professores da UERJ e do Centro Universitário Plínio Leite.

\section{Resumo:}

A presente pesquisa tem o propósito de examinar e caracterizar as escrituras de Sérgio Sant'Anna e João Gilberto Noll, em relação às projeções da cultura de massa na contemporaneidade. A partir de procedimentos intertextuais de leitura, observamse as estratégias utilizadas, nessas escrituras, para a transformação da linguagem romanesca em expediente visual híbrido, cujo princípio constitutivo é a técnica de colagem/montagem de diferentes ordens discursivas que, ao se 
imbricarem, relativizam as diferenças entre texto literário e artes audiovisuais. Acompanha-se interpretativamente o gesto dialógico que, como operação de leitura produtiva, promove a incorporação da visualidade e produz o efeito fílmico, processando, ao mesmo tempo, a recapitulação condensada de variados recortes discursivos.

Palavras-chave: Literatura, texto, imagem

Nas escrituras de Sérgio Sant'Anna e de João Gilberto Noll, um dado operatório de grande relevância é a exploração da linguagem em suas virtualidades visuais. Ambos se empenham em extrair um substrato imagético do signo verbal e o propósito parece ser o de alcançar o máximo de visualidade em linguagem escrita. O liame entre palavra e imagem, ao ser atualizado, forja identidades entre as duas práticas ficcionais. Ocorre nessas produções o que Roland Barthes chama de Babel feliz, pois nelas se torna patente a "coabitação de linguagens, que trabalham lado a lado"(1), a pluralidade de leituras e sentidos, a mescla do literário e do midiático, a simultaneidade dos planos verbal e fílmico. Nos dois autores, é, portanto, notória a apresentação do sistema textual como território híbrido, em que se ambienta o básico processo da cinematografia com a montagem, recurso pelo qual são construídas zonas de contato entre diferentes realidades discursivas. Do ato de sobrepor recortes discursivos, resulta não apenas o reagenciamento de fragmentos, a desestabilização de clichês, mas também o engendramento de uma dinamicidade que alicerça o trabalho de reduplicação, realizado com ênfase na imagem. Considerando dessa perspectiva as práticas escriturais dos referidos autores, busca-se, neste trabalho, examinar o jogo simulador da linguagem que promove a incorporação da visualidade e produz efeito de montagem, processando, concomitantemente, a recapitulação condensada de múltiplas convenções.

Inicialmente, o uso do termo montagem restringia-se ao âmbito das atividades cinematográficas, sendo empregado, como o é ainda hoje, para indicar "a organização dos planos de um filme em certas condições de ordem e de duração"(2). O cinema narrativo de Hollywood, após 1914, apresenta como característica fundamental uma notável prática no domínio da montagem dita invisível, cuja base é o culto à continuidade (logo, à neutralização do corte) e ao mecanismo de identificação, o que o torna capaz de seduzir o observador por meio de expedientes formais que buscam apagar os traços que o denunciam como discurso trabalhado. No extremo oposto dessa vertente, as proposições de Sergei Eisenstein, desde aproximadamente 1928, bem como de outros cineastas e críticos, 
apontam para direções contrárias ao exercício da montagem invisível. A tática de montagem, na perspectiva de Eisenstein, obedece ao princípio da disjunção, da descontinuidade realçada, definindo-se como franca oposição às convenções que regem o ilusionismo do cinema-janela.

No início deste século, por força do realce dado à fragmentação pelas vanguardas, o termo montagem passou a se referir a uma nova prática literária de articulação de signos, sentenças e/ou seqüências narrativas, que produz o efeito de simultaneidade e síntese, tornando condensada a linguagem. A principal estratégia assumida pelas vanguardas para a quebra de antigos moldes discursivos foi a montagem, que adquire poder de choque e de inovação. Sobre o assunto, veja-se o que diz Benedito Nunes:

As palavras em liberdade, a desarticulação da sintaxe e as imagens-choque, patrimônio comum das vanguardas das primeiras décadas do século particularmente utilizado pela geração que se convencionou chamar impropriamente a do "cubismo literário" (19171920), acham-se interligados no procedimento característico mais geral da arte moderna: a técnica de justaposição ou montagem, em que se relacionam elementos heterogêneos, sem ligações diretas entre si(3).

A partir da década de 60, com a expansão dos veículos de massa e das formas de comunicação coletiva por imagens, ocorre a banalização da técnica de montagem e a conseqüente perda de contundência da ruptura. A inflação dos espetáculos visuais esvazia a montagem de todo significado revolucionário. Ela se torna, por meio do mecanismo da repetição, um acontecimento trivial, uma experiência cotidiana constantemente reiterada num mundo cada vez mais cindido, frenético, recortado por estilhaços de imagens.

Em grande parte da produção de escritores contemporâneos, diferente do que ocorreu, com freqüência, na estética rebelde e hermética do modernismo, a montagem não se verifica no nível de palavras e frases, mas no nível de idéias-imagens. Despojada do tom provocativo das vanguardas, a montagem se torna essencialmente lúdica - jogo de relações descontínuas entre os constituintes textuais dissonantes e heterogêneos -, reafirmando o apelo à participação, em decorrência das pausas instauradas, que são verdadeiros ensejos ao trânsito livre de sentidos.

Tome-se, então, na escritura de João Gilberto Noll, como exemplo significativo de ruptura no plano da estruturação de idéias-imagens, a seqüência do romance Hotel Atlântico, em que se verifica o confronto entre o narrador-personagem e os assassinos do oeste catarinense, da qual o recorte a seguir faz parte: 
Comecei a fazer o caminho de volta, espreitando tudo a cada passo, quando vi os dois logo após uma rocha que vinha quase até a água, num trecho de margem especialmente lamacento. Recuei e me escondi atrás da rocha, por uma fenda eu via o que se passava. Nélson botava o cano de um revólver na testa de Léo. Léo sem camisa, ajoelhado na lama. Léo chorava. Nélson dizia se cuspindo. Se você não matar esse cara agora, eu é que acabo com você.

Esse cara é artista de novela, se ele quiser denuncia a gente pra polícia e com isso a fama dele aumenta. Como é que eu ia adivinhar que isso ia acontecer! E ele viu, não tem dúvida, ele viu.

Eu vi o quê?, pensei. Seria o sangue que eu tinha visto? Essa coisa que Nélson queria esconder me matando. Como fugir dali?(4).

Verifica-se, no episódio, que a montagem das rápidas seqüências de ação se dá totalmente fora das técnicas de continuidade. No texto lacunar, os fatos se apresentam desconectados: nada justifica a atitude dos assassinos; nenhuma das cenas já mostrada diz respeito ao fato de eles terem surpreendido o narrador vendo algo que os pudesse incriminar. O episódio mencionado não mantém conexão com outro, não decorre de algo anteriormente expresso, tampouco será posteriormente esclarecido. Na narrativa, o desenvolvimento "natural" e contínuo das ações é suprimido.

O narrador, ao apresentar a cena, não o faz como "senhor" da narração: aquele a quem interessa explicá-la e encaminhá-la de acordo com sua óptica lógica e centralizadora. Envolvido como participante, ele demonstra não possuir nenhum conhecimento que lhe permita elucidar enigmas. Tipicamente pós-moderno, o texto constrói uma primeira pessoa que está longe de possuir a onisciência e onipresença peculiar à narrativa clássica de caráter realista. Na escritura de Noll, as imagens que o olhosujeito projeta não encerram informações, ensinamentos e/ou explicações. Ao celebrar a instabilidade por meio de imagens descontínuas, esse olho, não regulado pelas regras da perspectiva, mantém-se contrário a uma lógica composicional, calcada na continuidade/profundidade.

Pensar a montagem literária, nos termos aqui apresentados processo operador de fragmentos que se baseia no corte, instaurando múltiplas direções significantes - é aproximá-la, de certa forma, do padrão de montagem eisensteiniano. Porém, na reabilitação desse esquema de montagem, ocorre um desalojamento da dimensão revolucionária que caracterizou a descontinuidade do cinediscurso reflexivo do cineasta russo.

A alusão ao gênero western, com seus pistoleiros rudes que cavalgam para lugares distantes e desconhecidos, fica explícita na seqüência mencionada, que se desenrola na Fazenda Oásis, quando o narrador-personagem se vê às voltas com os assassinos. Também a referência contemporânea se faz presente: 
os cavalos são substituídos pelo automóvel. Contudo, é interessante observar que a ação descrita no momento da fuga de carro, com seus sucessivos deslocamentos - análogos ao de uma câmera - , sugere o galopar de um cavalo. Apontando em direção a um passado que hoje existe como construção tipificada, a narrativa mantém um substrato comum a esse gênero: os lances de violência, a fuga, o enfrentamento de homens rudes e violentos, a desabalada carreira, a austeridade da natureza, que testemunha indiferente a valentia, são algumas das identidades incorporadas em relação à estrutura clássica do western. No entanto, os locais conhecidos do gênero retornam esvaziados de sua força inicial, banalizados na imagem condensada que reúne um desgastado repertório de artificios convencionais. As referências, que pertenciam a uma mensagem de prestígio, surgem deslocadas e vulgarizadas num contexto narrativo sincrético. Veja-se a seguir mais um trecho da seqüência:

Eu comecei a me arrastar por trás da rocha, subindo a ribanceira. Quando chegasse lá em cima eu correria o mais veloz possível, pois os cachorros iriam latir furiosos isso era certo, eu então teria que ser o mais veloz possível porque o latido dos cães me colocaria na mira da arma de Nélson em menos de segundos, o mais veloz possível eu correria e pegaria a chave em cima do painel do carro onde Nélson a deixara e eu tinha certeza, eu fugiria no carro, eu fugiria.

Eu me arrastava subindo a ribanceira, pegava em raízes expostas para me ajudar nos impulsos necessários para me fazer subir, 0 chão tinha a umidade de mato cerrado que nunca recebe a luz do sol, eu vinha subindo trazendo folhas das árvores coladas à roupa, todo enlameado, com movimentos medidos para não cometer o menor ruído, quando chegasse no topo da ribanceira aí não haveria saída, eu teria de correr, fazer barulho, ser veloz até o carro que estava próximo dos cães policiais que latiriam como possessos, esticando as correntes até um ponto que talvez arrebentassem(5).

A passagem, ironicamente estilizada, adota uma linguagem com acabamento, por assim dizer, artesanal. A expectativa ansiosa do narrador, no momento da fuga, é traduzida através de um discurso que tende para a elaboração estilística, no qual a escalada da ribanceira, que lhe possibilitaria alcançar o carro e tentar escapar, é apresentada em etapas, indicadas por alguns sintagmas que vão diminuindo sugestivamente de extensão à medida que o narrador se aproxima do topo: "Eu comecei a me arrastar por trás da rocha, subindo a ribanceira / Eu me arrastava subindo a ribanceira / eu vinha subindo". A redução parece expressar a progressiva concentração de esforços bem como o encurtamento do espaço a ser percorrido. Diante do perigo, o narrador que, até então só agia movido por estímulos externos, durante a subida, elabora hipóteses, planeja uma maneira de se livrar dos assassinos. 
A partir do momento em que o narrador-personagem põe o carro em movimento, a escritura presentifica a ação, de forma a construir o pânico também no leitor, levando-o assim a uma participação mais efetiva. Tome-se como ilustração o fragmento:

(...) vejo que um cachorro expulsa a sua fúria entre o carro e a pedra, e eu dou mais velocidade e esmago o cachorro contra a pedra, bato com o carro duas três vezes contra a pedra, esguicha sangue no parabrisa, desvio agora para a esquerda, um tiro estilhaça o vidro de trás, pego o caminho de terra enfim, dou toda velocidade, vou, vou, poeira, poeira de todos os cantos, quase perco a visão, o carro derrapa para fora do caminho de terra, vou, vou por onde der (...) (6).

Para ressaltar o ritmo acelerado da corrida e construir o efeito de simultaneidade, a narrativa, calcada na predominância de efeitos ópticos, empenha-se em adaptar à sua tessitura a velocidade; utiliza, então, uma série de recursos formais, entre eles: a repetição de vocábulos (vou, vou), a aliteração, por exemplo, do fonema /V/, a ausência de pontuação, o uso abundante de vocábulos curtos e o emprego predominante da parataxe. O procedimento de adotar apenas "momentaneamente" traços artesanais acentua o distanciamento da escritura em relação a tal prática que, neste caso, funciona apenas como mais um dado operatório, em meio a outros.

Nesse caso, paradoxalmente, o produto serial (o western), incorporado parcialmente pela técnica apropriativa do pastiche, é reelaborado através de uma linguagem que forja o artifício artesanal, comum à estética modernista. Fugindo a um esquema de estrutura discursiva unificadora, o método compósito da obra mescla indistintamente componentes textuais atenuados e desgastados de campos discursivos diversos e, por vezes, contraditórios e, com eles, estabelece uma ampla rede intertextual de referências múltiplas que, operando lado a lado, configuram o espaço narrativo como uma superfície plural e fragmentada.

Em Sérgio Sant'Anna, a montagem, em termos de idéias-imagens, assumida pelo conjunto da obra também torna a descontinuidade um procedimento localizável em diferentes planos da prática textual. Pode-se detectar o descompromisso com a linearidade e a insurgência do caráter paratático da montagem, por exemplo, na seqüência de "entrada" de A tragédia brasileira, em que os elementos textuais são mostrados em planos justapostos: o túmulo de Jacira, Jacira, o Poeta, a cadeira de balanço, o cemitério, o encontro entre Jacira e o Poeta. Os episódios que se sucedem não se vinculam a um ordenamento causal. Não há, entre os constituintes discursivos, elos explicativos que os relacionem ou hierarquizem de forma definida. 
O trecho a seguir assinala a abertura de A tragédia brasileira: romance-teatro, de Sérgio Sant'Anna. Nele, bem como em todo o restante do romance, a perspectiva textual dentro da qual se inscreve a fala do narrador funciona como um trabalho de linguagem que, além de manter similaridades com um espetáculo teatral, desencadeia efeitos visuais com características cinematográficas:

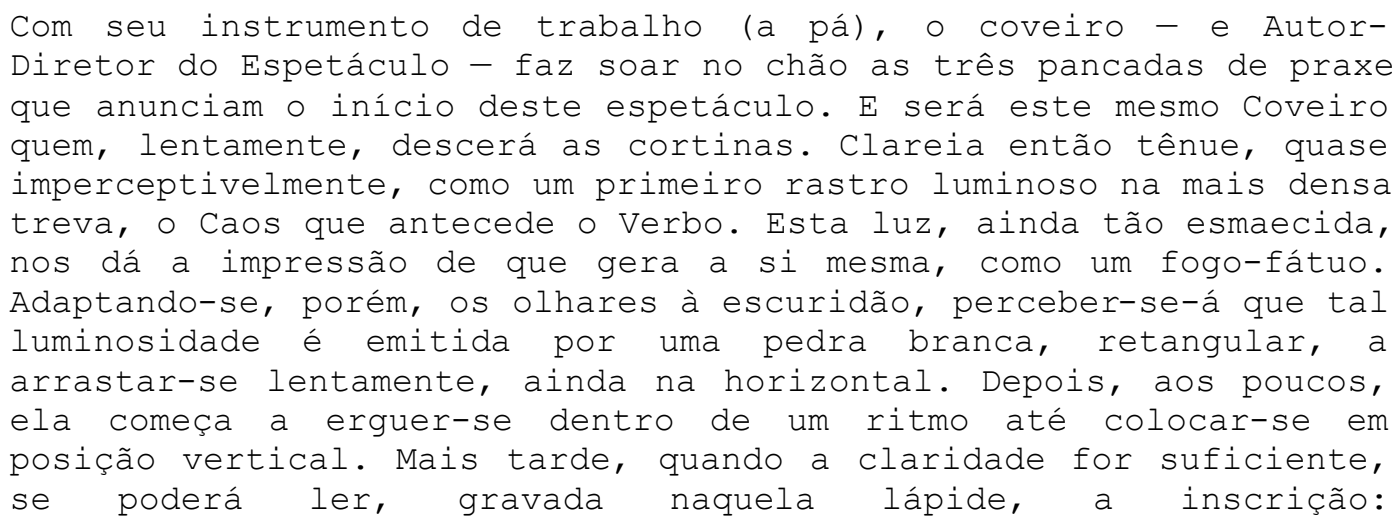

Ao anjinho Jacira, a nossa saudade eterna (7) .

A prática romanesca simula a apresentação de uma peça que se desenvolve a partir de uma situação francamente imaginária, como mostra o pequeno texto introdutório, com feição de prólogo:

Esta é a história de um espetáculo imaginário. Um espetáculo que poderia se passar, por exemplo, no interior do cérebro de alguém que fechasse os olhos para fabricar imagens e delas desfrutar, diante de uma tela ou palco interiores, como um sonho, só que não de todo inconscientemente ordenado (8).

A seqüência inicial é estruturada de modo a servir de possível suporte a diversas leituras. Por um lado, porque sua organização é lacunar, enigmática e aberta: são descartados os encadeamentos lógicos, a nitidez cronológica, a caracterização precisa dos lugares e das personagens. Por outro, porque suas opções formais/técnicas, ligadas - via processo de simulação pela prática da paródia e/ou do pastiche - a dadas estratégias do cinema expressionista alemão, favorecem a emergência do simbólico: o "plano" marcado pela não definição da totalidade, num forte contraste entre zonas visiveis e zonas mergulhadas nas trevas, ausência de falas entre os personagens, valorização de certos objetos, papel da música, tudo isso concorre para dotar as imagens descontínuas de densidade de sentido.

Em A tragédia brasileira, a narrativa progride para uma utilização cada vez mais descontínua da montagem, evolução esta que culmina na estonteante seqüência do epílogo, em que a lógica espaço-temporal e os padrões usuais de causalidade são 
desfeitos, em favor de uma intensa fragmentação que, tornando impossível a concatenação das idéias-imagens num fio lógico linear, desarticula irremediavelmente o discurso. Há no texto momentos em que o mecanismo de montagem é explicitado, com distanciamento irônico, pelo Autor-Diretor que, funcionando ambiguamente como narrador, situa personagens, cenários e episódios num contexto cênico caótico:

\begin{abstract}
Instaura-se, então, dentro do espaço-cênico, outro espaço que são as associações e imagens que atravessam fulminantemente o cérebro de Cristo (...) Mas por uma superposição compensatória de imagens, logo instaura-se na mente de cristo a visão de catacumbas onde seus seguidores, na clandestinidade, entoam fervorosos cânticos de louvor a ele, Jesus Cristo (9).
\end{abstract}

As análises precedentes mostraram, fundamentalmente, que ambas as escrituras adotam, em seu projeto estético, os recursos da visualidade e da montagem. Mas embora tomem de empréstimo temas e técnicas da indústria cultural como componentes estruturais, deixando-se marcar pelo padrão técnico, elas o ultrapassam, já que, voltadas para a natureza lúdica da linguagem, cultivam uma margem de ambigüidade que propicia a mobilidade do sentido e a incorporação do receptor no ato de produção criativa, diferenciando-se, assim, do que é tido como mero consumo.

A integração de expedientes múltiplos na polifonia da escritura desdobra o estatuto da recepção: o texto não se oferece apenas à simples leitura, mas também à apreensão visual, já que ganha, com a estratégia de hibridização, um contorno imagético. Há, portanto, um outro mecanismo implicado nessa operação: o texto, adaptado à linguagem e às categorias da mídia, pode ser encarado, na sua versão "midiatizada", como um processo tradutório, pois sua construção em linguagem verbal inclui um percurso intersemiótico realizado a partir da intervenção de diferentes linguagens, submetidas a aproveitamentos diversos.

Recorrendo a estratégias semelhantes quanto à apreensão do cinematográfico, as escrituras de Sérgio Sant'Anna e João Gilberto Noll diferenciam-se quanto aos objetivos buscados com - jogo articulatório entre linguagens e o agenciamento de recortes discursivos de diferentes códigos que definem a prática da tradução em cada autor.

No corpo disjunto da narrativa de Sant'Anna, sob a ação determinante da auto-reflexividade, a escritura combina o recurso da montagem com a elaboração discursiva. Nesse sentido, pode-se dizer que há nela uma certa reafirmação do impulso autêntico de uma tradição modernista, traduzida na disseminação, na mistura e na variação de formas poéticas. optando por acionar mecanismos de logro, a escritura se apraz 
em gerar jogos paradoxais entre aceitação e transgressão das formas e dos modelos pertinentes às linguagens incorporadas. Em dados momentos, a intensificação de certas rubricas linguageiras leva ao estilhaçamento da moldura revisitada e, dessa maneira, forja expedientes que introduzem outros registros, nos quais o caricatural acaba por instaurar o inédito. Logo, entre os constituintes textuais, não se estabelece nenhuma combinação ou síntese. Pelo contrário, eles se entremeiam num coexistir problemático, questionador, indefinível, pleno de ardis e potencialidades expressivas.

Comparada à escritura de Sant'Anna, a de Noll trata da montagem com uma outra perspectiva. A fragmentação na narrativa de Noll não implica experiências escriturais vinculadas a um tipo de jogo cifrado, em que o paradoxo, os mecanismos de confronto e de trapaça são os expedientes básicos. Sua finalidade específica é, antes, a de ampliar o campo expressivo do alcance visual, o que proporciona juntamente com outros fatores, como afirma José Castello, "uma leitura sempre seca, frontal, sem melindres e sem adjetivos, trançada numa linguagem visual, quase transparente, em que as palavras quase não são notadas de tal modo somos arrebatados pelas imagens" (10).

Enquanto em Sant'Anna, o valor estratégico da fragmentação deve abrigar a expressividade que um trabalho apurado de torneamento das formas narrativas requer, em Noll, a fragmentação, lembrando flashes, vale pelo efeito de cintilação, de exterioridade brilhante. "E O romance desagrega. De repente a voz da trama torna-se átomos cintilantes. Microscópicas esferas soltando faíscas. Por todos os poros" (11), pelo poder de gerar um ritmo eletrizante - e nele a volúpia da visualidade -, pelo efeito de instantaneidade e simultaneidade arrebatadora, pelo impacto imediato, pela fixação nas aparências, nas impressões superficiais e casuais.

À luz do que foi apresentado, é importante ressaltar que as escrituras de Sant'Anna e Noll, tendo surgido em momentos diferentes (respectivamente, 1969 e 1980) e estando hoje lado a lado no contexto pós-moderno, apresentam feições diversas, apesar de traços análogos. Se as duas recebem o influxo do cinema, esse processo, que passa pela incorporação da visualidade e da montagem, faz parte de um diálogo intertextual que, partindo, em ambos os casos, de uma identificação primeira com o padrão industrial, busca caminhos distintos. Em Sant'Anna, esse diálogo é submetido a uma refinada transcodificação, realizada de acordo com uma operação tradutória que se quer elaborada e que, por isso mesmo, tende a tornar singular a sintaxe textual; em Noll, a relação dialógica com a técnica industrial, seguindo uma outra 
via, busca um modo de transcodificação aparentemente despojado que, nesse caso, efetua-se segundo uma concepção de produto artístico desindividualizado.

\section{Abstract}

The purpose of this research is to examine and characterize the writings of Sérgio Sant'Anna and João Gilberto Noll in relation to mass culture nowadays. From intertextual reading procedures, we can observe the strategies used in their writings to transform the romanesque language into a hybrid visual product whose constitutive principle is the collage/assembly technique of different discursive orders. When these discursive orders overlap, the differences between the literary text and the audiovisual arts are relativized. This dialogical gesture will be interpreted as a useful reading technique, for it promotes the incorporation of visualization and produces the filmic effect by processing simultaneously the condensed recapitulation of various discursive incisions.

Key Words Literature, text, image

\section{Notas}

[1] BARTHES, 1977, p. 8 .

[2] MARTIN, 1985, p. 132.

[3] NUNES, 1975, p. 45.

[4] NOLL, 1989, p. 46-47.

[5] NOLL, 1989, p. 47.

[6] NOLL, 1989, p. 48.

[7] SANT'ANNA, 1987, p. 9.

[8] SANT'ANNA, 1987, p. 5.

[9] SANT'ANNA, 1987, p. 155.

[10] CASTELLO, 1989, p. 7.

[11] NOLL, 1985, p. 87.

\section{Bibliografia}

BARTHES, Roland. O prazer do texto. São Paulo: Perspectiva, 1977. CASTELLO, José. Noll golpeia os leitores com seu olhar.Jornal do Brasil, Rio de Janeiro, $1^{\circ}$ de abril de 1989, Caderno Idéias, p.7-9. MARTIN, Marcel. A linguagem cinematográfica. São Paulo: Brasiliense, 1990. NOLL, João Gilberto. Bandoleiros. Rio de Janeiro: Nova Fronteira, 1985. - Hotel Atlântico. Rio de Janeiro: Rocco, 1989. NUNES, Benedito. Estética e correntes do modernismo. In: ÁVILA, Afonso (Org.) O modernismo. São Paulo: Perspectiva, 1975. SANT'ANNA, Sérgio. A tragédia brasileira: romance-teatro. Rio de Janeiro: Guanabara, 1987. 